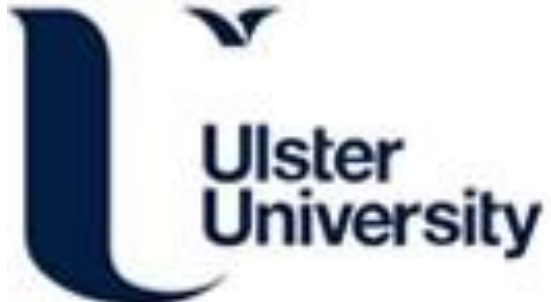

\section{Electrospinning 3D bioactive glasses for wound healing}

Norris, E., Ramos-Rivera, C., Poologasundarampillai, G., Clark, J., Ju, Q., Obata, A., Hanna, J., Kasuga, T., Mitchell, C. A., Jell, G., \& Jones, J. R. (2019). Electrospinning 3D bioactive glasses for wound healing. Biomedical Materials, [BMM-103113.R1]. https://doi.org/10.1088/1748-605X/ab591d

Link to publication record in Ulster University Research Portal

\section{Published in:}

Biomedical Materials

Publication Status:

Published online: 19/12/2019

DOI:

10.1088/1748-605X/ab591d

\section{Document Version}

Author Accepted version

\section{General rights}

Copyright for the publications made accessible via Ulster University's Research Portal is retained by the author(s) and / or other copyright owners and it is a condition of accessing these publications that users recognise and abide by the legal requirements associated with these rights.

\section{Take down policy}

The Research Portal is Ulster University's institutional repository that provides access to Ulster's research outputs. Every effort has been made to ensure that content in the Research Portal does not infringe any person's rights, or applicable UK laws. If you discover content in the Research Portal that you believe breaches copyright or violates any law, please contact pure-support@ulster.ac.uk. 
ACCEPTED MANUSCRIPT

\section{Electrospinning 3D bioactive glasses for wound healing}

To cite this article before publication: Elizabeth Norris et al 2019 Biomed. Mater. in press https://doi.org/10.1088/1748-605X/ab591d

\section{Manuscript version: Accepted Manuscript}

Accepted Manuscript is "the version of the article accepted for publication including all changes made as a result of the peer review process, and which may also include the addition to the article by IOP Publishing of a header, an article ID, a cover sheet and/or an 'Accepted Manuscript' watermark, but excluding any other editing, typesetting or other changes made by IOP Publishing and/or its licensors"

This Accepted Manuscript is @ 2019 IOP Publishing Ltd.

During the embargo period (the 12 month period from the publication of the Version of Record of this article), the Accepted Manuscript is fully protected by copyright and cannot be reused or reposted elsewhere.

As the Version of Record of this article is going to be / has been published on a subscription basis, this Accepted Manuscript is available for reuse under a CC BY-NC-ND 3.0 licence after the 12 month embargo period.

After the embargo period, everyone is permitted to use copy and redistribute this article for non-commercial purposes only, provided that they adhere to all the terms of the licence https://creativecommons.org/licences/by-nc-nd/3.0

Although reasonable endeavours have been taken to obtain all necessary permissions from third parties to include their copyrighted content within this article, their full citation and copyright line may not be present in this Accepted Manuscript version. Before using any content from this article, please refer to the Version of Record on IOPscience once published for full citation and copyright details, as permissions will likely be required. All third party content is fully copyright protected, unless specifically stated otherwise in the figure caption in the Version of Record.

View the article online for updates and enhancements. 


\title{
Electrospinning 3D bioactive glasses for wound healing
}

\author{
Elizabeth Norris ${ }^{1}$, Carolina Ramos-Rivera ${ }^{2}$, Gowsihan Poologasundarampillai ${ }^{3}$, Joshua P. Clark ${ }^{4}$, Qun Ju ${ }^{5}$, Akiko
} Obata $^{5}$, John V. Hanna ${ }^{4}$, Toshihiro Kasuga ${ }^{5}$, Christopher A. Mitchell ${ }^{6}$, Gavin Jell ${ }^{2}$ and Julian R. Jones ${ }^{1 *}$ ${ }^{1}$ Department of Materials, Imperial College London, South Kensington Campus, London, SW7 2AZ, $\mathrm{UK}$;

${ }^{2}$ Royal Free Medical School, Division of Surgery, University College London, UK;

${ }^{3}$ School of Dentistry, University of Birmingham, Birmingham, UK

${ }^{4}$ Department of Physics, University of Warwick, Gibbet Hill Rd., Coventry CV4 7AL, UK

${ }^{5}$ Graduate School of Engineering, Nagoya Institute of Technology, Gokiso-cho, Showa-ku, Nagoya 466-8555, Japan

${ }^{6}$ School of Biomedical Sciences, Ulster University, Cromore Road, Coleraine Co., Londonderry BT52 1SA, UK

E-mail: julian.r.jones@imperial.ac.uk

Received xxxxxx

Accepted for publication $\mathrm{xxxxxx}$

Published xxxxxx

\begin{abstract}
An electrospinning technique was used to produce three-dimensional (3D) bioactive glass fibrous scaffolds, in the $\mathrm{SiO}_{2}-\mathrm{CaO}$ system, for wound healing applications. Previously, it was thought that $3 \mathrm{D}$ cotton wool-like structures could only be produced when the sol contained calcium nitrate, implying that the $\mathrm{Ca}^{2+}$ and its electronic charge had a significant effect on the structure produced. Here, fibres with a 3D appearance were also electrospun from compositions containing only silica. A polymer binding agent was added to inorganic sol-gel solutions, enabling electrospinning prior to bioactive glass network formation and the polymer was removed by calcination. While the addition of $\mathrm{Ca}^{2+}$ contributes to the $3 \mathrm{D}$ morphology, here we show that other factors, such as relative humidity, play an important role in producing the $3 \mathrm{D}$ cotton-wool-like macrostructure of the fibres. A human dermal fibroblast cell line (CD-18CO) was exposed to dissolution products of the samples. Cell proliferation and metabolic activity tests were carried out and a VEGF ELISA showed a significant increase in VEGF production in cells exposed to the bioactive glass samples compared to control in DMEM. A novel $\mathrm{SiO}_{2}-\mathrm{CaO}$ nanofibrous scaffold was created that showed tailorable physical and dissolution properties, the control and composition of these release products are important for directing desirable wound healing interactions.
\end{abstract}

Keywords: Electrospinning, Sol-gel, Bioactive glasses, 3D cotton-wool-like structure, Wound healing

\section{Introduction}

The successful treatment of wounds is a growing challenge for healthcare systems worldwide. In the UK alone, the National Health Service (NHS) treated an estimated 2.2 million wounds in 2012/2013 costing a total of $£ 5.3$ billion for the management and associated comorbidities of the wounds [1].

Wounds that fail to heal in a timely manner or progress through the normal stages of healing are known as chronic wounds. Chronic wounds typically occur as complications from underlying health conditions such as foot ulcers in patients with diabetes [2]. Factors such as age, lifestyle and 
medication can also increase the likelihood of occurrence [3] [4]. Chronic wounds typically experience prolonged or excessive inflammation and are at risk from persistent infections [5].

Clinical procedures for healing chronic wounds commonly include compression therapies, skin substitutes or dressings [6]. Tissue-engineered products [7], such as allograft-based bilayered cultured skin equivalents exist, e.g. Apligraf ${ }^{\circledR}$ (Organogenesis), which combines a dermal layer of cultured fibroblasts and bovine type I collagen with an epidermal layer of cultured keratinocytes, producing epidermis [8-9] and an environment similar to that of a normal healing wound [6]. While this produces a well-differentiated epidermis and dermis, it misses some of the components found in healthy skin, such as pigments, hair follicles, sweat glands and immune cells [9]. Tissue engineering is expensive and time consuming [10], therefore cost efficient biodegradable devices are needed which can be used with conventional dressings and stimulate healing of chronic wounds.

Bioactive glasses are biodegradable devices that have traditionally been used in bone regeneration [11-12]. Bioactive glasses can also bond to soft tissue [13] and the original bioactive glass composition, $45 \mathrm{wt} \% \mathrm{SiO}_{2}, 24.5 \mathrm{wt} \%$ $\mathrm{CaO}, 24.5 \mathrm{wt} \% \mathrm{Na}_{2} \mathrm{O}$, and $6.0 \mathrm{wt} \% \mathrm{P}_{2} \mathrm{O}_{5}$, known as $45 \mathrm{~S} 5$ Bioglass ${ }^{\circledR}$ [14] , developed by Hench [14-15], has been investigated for wound healing [17] [18]. Day et al. [19] demonstrated that $45 \mathrm{~S} 5$ can stimulate the expression and release of VEGF and $\beta$-FGF by $\mathrm{CD}-18 \mathrm{Co}$ human fibroblasts, suggesting that by the release of growth factors, Bioglass could potentially stimulate neovascularisation. Other bioactive glass compositions may also stimulate VEGF, providing an application for bioactive glasses in wound healing.

Mo-Sci Corp. (Rolla, MO) developed borate based melt derived bioactive glass fibres which have a 3D appearance similar to cotton-wool (Mirragen ${ }^{\circledR}$, ETS Woundcare, Rolla, MO). They used a melt blowing technique [20] [21] to produce borate glass fibres and the device showed successful clinical results in healing diabetic foot ulcers that were not healing under conventional treatment [22]. Importantly, the device was not a dressing: the cotton wool-like glass was packed into the wound bed and a dressing was placed over it and the wound. The device and the dressing were replaced approximately every two days. The aim here was to produce a silicate based bioactive glass scaffold cotton wool-like device with tighter control over the fibre diameter and to carry out preliminary cell studies to investigate its potential for wound healing applications. Combination of the sol-gel process and the electrospinning technique were hypothesised to give tight control over the glass composition and fibre diameter.

Sol-gel derived silica glasses are made through the hydrolysis of alkoxide precursors, to make a sol, and gelation through polycondensation of silicate species [23]. They have an inherent nanoporosity [21], which increases the surface area of the glass compared with dense melt-derived glasses. This enables control over the dissolution rates [20] of the glasses which is beneficial for wound healing applications, where short recovery times are imperative [4]. There are various methods for processing of sol-gel glasses into $3 \mathrm{D}$ macrostructures, such as by foaming [24] or as fibres [25].

Electrospinning can be used to make fibrous structures at a scale that can mimic some of the key structural features of the extracellular matrix (ECM) [26] [27] of the skin [28], [29]. The collagen fibrous structure is formed by multi-fibrils, organised in a three-dimensional fibre network.

Electrospinning is versatile [30] but typically produces a $2 \mathrm{D}$ fibremat structure, which could be used in shallow wounds [31]. Poologasundarampillai et al. [25] electrospun a sol-gel $70 \mathrm{~mol} \% \mathrm{SiO}_{2}$ and $30 \mathrm{~mol} \% \mathrm{CaO}$ (70S30C) bioactive glass composition directly from the sol and produced a 3D structure that had an appearance similar to cotton-wool or cotton candy. Their focus was on bone regeneration and bioactivity with scaffolds of high $\mathrm{Ca}$ content for bone bonding and mineralisation. With the ability to be packed into spaces, the morphology may be more suitable for deep wounds in the skin. The production of a 3D structure with new compositions and the potential to mimic the natural extracellular matrix could potentially impact the behaviour and proliferation of cells [32]. This ' $3 \mathrm{D}$ ' structure is different from some literature definitions which define ' $3 \mathrm{D}$ ' as $2 \mathrm{D}$ fibremats which are thicker $(\sim 0.5-2 \mathrm{~mm})$ than conventional fibremats $(<0.5 \mathrm{~mm})$ [33], [34].

The formation of a 3D structure was attributed to two factors: i) the rheological properties and surface tension of the sol; ii) the distribution of conductive ionic species $\left(\mathrm{Ca}^{2+}\right.$ ions). They proposed that the application of an electric field to the 70S30C sol caused the separation of calcium and silicate ions resulting in a heterogeneous distribution of $\mathrm{Ca}^{2+}$ and $\mathrm{SiO}_{4}{ }^{4-}$ at the Taylor cone. The position and quantity of separated charges at the cone determines the forces on the fibres as they spin and consequentially affects how the fibres are whipped as they move towards the collector plate. A similar effect was produced by electrospinning certain polymers [35], [36], e.g. polyaniline, when an external electric field concentrates charge carriers at favourable points within fibres through a conductive medium. Spinning a $100 \mathrm{~S}$ sol $\left(100 \mathrm{~mol}^{2} \mathrm{SiO}_{2}\right)$ composition, not containing $\mathrm{Ca}$ ions, produced the traditional, 2D structure.

Our hypothesis here was that more parameters affect the morphology of the scaffolds, such as the solution viscosity [37]; the voltage applied and distance between the needle tip and the collector plate [29], [36]. Environmental factors such as the relative humidity [27-29] and temperature [41] of the surroundings can also affect the morphology of electrospun fibres. Our initial studies on electrospinning sol-gel, found the viscosity to be partly dependent on the degree of crosslinking 
(gelation) induced by the hydrolysis and condensation of the silica sol-gel network [37] and partly by the amount of polyvinyal butryal additive used.

Here, the aim was to develop a robust protocol for production of a bioactive glass scaffold with a $3 \mathrm{D}$ porous structure intended for use in wound healing and to investigate VEGF production by a human dermal fibroblast cell line (CD18CO). The role of calcium in the fibres was a key focus so the quantity of calcium was varied compositions of $0-40$ $\mathrm{mol} \% \mathrm{CaO}$.

\section{Materials and methods}

\subsection{Sample preparation}

All reagents were obtained from Sigma-Aldrich (UK) unless otherwise stated. An electrospinning step was added to the conventional sol-gel process. Bioactive glass sols were produced with nominal compositions based on the 100 $\mathrm{XSiO}_{2}-\mathrm{XCaO}$ system (molar ratios, coded 100-XSXC), 100S, 60S40C, 70S30C, 80S20C and 90S10C. Sols were produced by mixing tetraethyl orthosilicate (TEOS), ethanol, water with $1 \mathrm{M}$ nitric acid $\left(\mathrm{HNO}_{3}\right)$ using a magnetic stirrer. Calcium nitrate tetrahydrate was added after $1 \mathrm{~h}$ (Table 1). The sol was stirred at room temperature for $24 \mathrm{~h}$ and then left to rest for a following $24 \mathrm{~h}$. Polyvinylbutyral (Butvar-98) was combined in equal parts with the sol, in order to obtain a viscosity within the range for electrospinning long continuous fibres of 0.56 0.95 Pa.s, as identified by Poologasundarampillai et al. [25]. An AntonPar Compact Rheometer MCR was used to measure viscosity. $1 \mathrm{~mL}$ of solution was placed on the centre of the dish before a flat-headed probe was automatically lowered onto the sample. Twelve readings for viscosity were taken per sample.

The hybrid solution was loaded into a plastic syringe with a gauge 22 stainless steel needle which was connected to a high voltage power supply set at $10 \mathrm{kV}$. A syringe pump was used at a feed rate of $0.4 \mathrm{~mL} \mathrm{~h}^{-1}$. The sol was electrospun onto a ground aluminium foil sheet at a distance of 100-120 mm from the end of the needle. The fibres were transferred to a ceramic container for stabilisation, where they were heated to $600^{\circ} \mathrm{C}$ at a rate of $1{ }^{\circ} \mathrm{C} \min ^{-1}$ with a dwell at $600{ }^{\circ} \mathrm{C}$ for $3 \mathrm{~h}$ before cooling naturally.

\subsection{Morphology and physical structure}

Relative humidity was measured using a humidity monitor, and was taken with each sample at the start and end of every electrospinning session. If electrospinning took place over a number of hours, and the relative humidity had changed, an average of several results was taken. The chemical compositions of the samples were determined through the use of a lithium metaborate flux: $50 \mathrm{mg}$ of the glass fibers were combined with $150 \mathrm{mg}$ of the lithium metaborate in a platinum crucible and heated in to $1050{ }^{\circ} \mathrm{C}$. When cooled the combination of flux and sample was dissolved in $2 \mathrm{M}$ nitric acid. The dissolved sample was then analysed using inductively coupled plasma-optical emission spectroscopy (ICP-OES) to determine the actually composition of the samples produced.

Scanning electron microscopy (SEM) was used to produce images of the fibres (JEOL-6V and LEO-1525). Samples were sputter coated with chromium to a maximum coating of 20 $\mathrm{nm}$, and were observed under a $5 \mathrm{kV}$ accelerating voltage and at a working distance of $8 \mathrm{~mm}$. Fibre diameters were measured $(\mathrm{n}=10)$ from SEM and analysed on ImageJ.

Nitrogen sorption (Autosorb1; Quantachrome, Fleet, UK) was used to investigate the surface area and the mesoporosity of the electrospun bioactive glass samples after degassing for at least $12 \mathrm{~h}$. Attenuated total reflectance-Fourier transform infrared spectroscopy (ATR-FTIR Nicolet iS10) and X-ray diffraction (XRD, Bruker D2 PHASER) were carried out on the bioactive glass. XRD uses a step scanning with $\mathrm{Cu}$ radiation, at $30 \mathrm{kV}$ and $10 \mathrm{~mA}$, with $0.035^{\circ} 2 \theta$ step size and a count rate of 12 second per step, from $6^{\circ}$ to $70^{\circ} 2 \theta$. FTIR spectra were collected in absorbance mode using a diamond ATR accessory in the range of $500-4000 \mathrm{~cm}^{-1}$.

Solid-state ${ }^{29} \mathrm{Si}$ magic angle spinning nuclear magnetic resonance (MAS-NMR) was used to measure the atomic and chemical structure of the bioactive glass fibres. The fibres were ground into a powder and samples were recorded on a 7.0 T Varian/Chemagnetics InfinityPlus spectrometer operating at $59.62 \mathrm{MHz}$. A Bruker $7 \mathrm{~mm}$ probe was used with an MAS frequency of $5 \mathrm{kHz}$. Single pulse acquisition used a minimum of 230 transients (depending on sample amount) and were collected using a $\pi / 2\left({ }^{29} \mathrm{Si}\right)$ pulse of $4.3 \mu \mathrm{s}$ with a 240 s recycle delay. In addition, ${ }^{1} \mathrm{H}(71 \mathrm{kHz})$ radiofrequency $(\mathrm{RF})$ decoupling was utilised during the acquisition. Deconvolution using OriginPro (OriginLab Corp.) isotropic chemical shift assignment was obtained from cross polarization measurements where a $\pi / 2\left({ }^{1} \mathrm{H}\right)$ of $3.5 \mu$ s and a contact time of $4 \mathrm{~ms}$ were optimised on the chemical shift reference (kaolinite, $-92 \mathrm{ppm}$ ) in addition to the aforementioned decoupling.

\subsection{Ion concentration}

The ion concentration of the samples was measured to ascertain the concentration of ions released into the samples after the samples were placed in media conducted in $5 \mathrm{mM}$ tris(hydroxymethyl)aminomethane, (TRIS) $\left(\left(\mathrm{CH}_{2} \mathrm{OH}\right)_{3} \mathrm{CNH}_{2}\right)$ buffer solution. In the study, $37.5 \mathrm{mg}$ of 70S30C and 80S20C $3 \mathrm{D}$ cotton-wool-like fibres were immersed in $25 \mathrm{~mL}$ of TRIS buffer solution, and stored in an incubator shaker at $37{ }^{\circ} \mathrm{C}$ and $120 \mathrm{rpm}$ according to the recommendations of Maçon et al. [42], all samples were produced in triplicate. A quantity of 0.5 $\mathrm{mL}$ of TRIS supernatant from each sample was collected at each time point $(0.5,1,2,3,4,8,24,48,72,96$, and $168 \mathrm{~h})$ for ICP-AES analysis and then $0.5 \mathrm{~mL}$ of fresh TRIS was added to keep the volume of the solution $25 \mathrm{~mL}$. Prior to ICP analysis the $0.5 \mathrm{~mL}$ of sample removed was filtered with a 0.2 
$\mu \mathrm{m}$ surfactant-free cellulose acetate filter (Corning, USA) and diluted with $4.5 \mathrm{~mL}$ of $2 \mathrm{M}$ nitric acid. Samples were analysed using ICP-AES analysis at wavelengths of $317.9 \mathrm{~nm}(\mathrm{Ca})$ and $251.6 \mathrm{~nm}(\mathrm{Si})$. The $\mathrm{pH}$ of each sample was measured at each time point by a pH meter with a thermal probe (Oakton $\mathrm{pH} 11$ meter with Oakton general purpose glass $\mathrm{pH}$ probe, $\mathrm{Ag} / \mathrm{AgCl}$ electrode, and Oakton ATC probe) attached to it.

Table 1. Summary of the electrospinning solution properties and conditions used for each sol composition (100-X SiO 2 , $\mathrm{XCaO}$ ). All samples had the same voltage, flow rate, distance between the collector plate and viscosity. These were set up to be $10.0 \mathrm{kV}, 0.4 \mathrm{~mL} / \mathrm{h}, 100-120 \mathrm{~mm}$ and $0.12-0.20 \mathrm{~Pa}$.s respectively.

\begin{tabular}{cccccc}
\hline Composition & TEOS $[\mathrm{mL}]$ & Nitric acid $[\mathrm{mL}]$ & Ethanol $[\mathrm{mL}]$ & $\mathrm{Ca}\left(\mathrm{NO}_{3}\right)_{2} \bullet 4 \mathrm{H}_{2} \mathrm{O}[\mathrm{g}]$ & Water $[\mathrm{mL}]$ \\
\hline $60 S 40 \mathrm{C}$ & 6.2 & 1.5 & 3.1 & 4.3 & 0.0 \\
$70 S 30 \mathrm{C}$ & 7.2 & 1.7 & 3.7 & 3.2 & 0.0 \\
$80 S 20 \mathrm{C}$ & 8.2 & 1.9 & 4.2 & 2.1 & 0.3 \\
$90 S 10 \mathrm{C}$ & 9.3 & 2.2 & 4.8 & 1.1 & 0.7 \\
100S & 7.2 & 1.7 & 3.7 & - & \\
\hline
\end{tabular}

To understand the concentration of ions that cells will encounter, the ion concentration study was repeated in Dulbecco's Modified Eagle's Medium (DMEM). $37.5 \mathrm{mg}$ of 70S30C and 80S20C 3D cotton-wool-like fibres were immersed in $25 \mathrm{~mL}$ of DMEM for 1-168 $\mathrm{h}$.

The immersed samples were kept in an incubator at $36.5^{\circ} \mathrm{C}$ to mimic physiological conditions. A quantity of $1 \mathrm{~mL}$ of DMEM supernatant was collected from each sample at each time point $(4,24,72$ and $168 \mathrm{~h})$ and filtered for ICP-AES analysis and then $1 \mathrm{~mL}$ of fresh DMEM was added to each sample to keep the solution volume at $25 \mathrm{~mL}$. Solid sample was collected from the filters, washed with PBS and rinsed with deionised water, and then dried at $40^{\circ} \mathrm{C}$.

\subsection{Cell studies}

A CD-18CO cell line (ATCC, UK) was expanded in DMEM supplemented with $10 \%(\mathrm{v} / \mathrm{v})$ foetal bovine serum (FBS), $1 \%$ penicillin streptomycin.

For cell culture, electrospun 70S30C and 80S20C cottonwool-like scaffolds were preconditioned in DMEM for $4 \mathrm{~h}$ in an atmosphere of $37^{\circ} \mathrm{C}, 5 \% \mathrm{CO}_{2}$ and $21 \% \mathrm{O}_{2}$. After $4 \mathrm{~h}$, the media was filtered using sterile $0.2 \mu \mathrm{m}$ filters to remove all fibres from the dissolution product. The dissolution product was later supplemented with $10 \%(\mathrm{v} / \mathrm{v})$ FBS and $1 \%(\mathrm{v} / \mathrm{v})$ penicillin/streptomycin. A Si control was also prepared from sodium metasilicate based upon the $\mathrm{Si} \mathrm{ppm}$ value at $4 \mathrm{~h}$ in DMEM for the $70 \mathrm{~S} 30 \mathrm{C}$ and $80 \mathrm{~S} 20 \mathrm{C}$, an average of these values was used to determine the quantity of sodium metasilicate used for the Si Control sample. The Si control was conducted to understand if there was a correlation between increase the silica and increasing cell proliferation. The $\mathrm{Si}$ was used to compare to see if the bioactive glass (with its $\mathrm{Si}$ and $\mathrm{Ca}$ components) is beneficial or if it is the silica alone which provides the benefit. A DMEM vehicle control was also produced alongside the $\mathrm{Si}$ control. This was comprised of DMEM supplemented with $10 \%(\mathrm{v} / \mathrm{v})$ FBS and $1 \%(\mathrm{v} / \mathrm{v})$ penicillin/streptomycin.

CD-18CO cells were suspended in DMEM at a concentration of 20,000 cells per $\mathrm{mL} .500 \mu \mathrm{L}$ of cell suspension was added to each well in a 48 well-plate. After 18 $\mathrm{h}$, the cell media was replaced with the supplemented 70S30C and 80S20C dissolution product and DMEM was used as control. At day 1, 3 and 7, the supernatant was collected for further analysis and metabolic activity was tested using AlamarBlue ${ }^{\circledR}$ cell viability (Thermo Fisher Scientific, USA) reagent at a $10 \%$ concentration in each conditioned media. Following an incubation period of $4 \mathrm{~h}, 200 \mu \mathrm{L}$ of the solution was transferred into a black well plate and fluorescence was measured at an excitation wavelength of $540 \mathrm{~nm}$ and an emission wavelength of $620 \mathrm{~nm}$ using a fluorescent microplate reader (Fluoroskan Ascent FL, Thermo Labsystems, UK).

Total DNA (tDNA) was quantified using the Hoeschst H332598 fluorescent dye according to manufacture instructions (Total DNA, Sigma-Aldrich, UK). After the AlamarBlue $^{\circledR}$ cell viability reagent was removed, the cells were washed with PBS and $200 \mu \mathrm{L}$ of $\mathrm{DI}_{2} \mathrm{O}$ was added to each cell well. The cells were then lysed with 5 freeze-thaw cycles. A standard curve was prepared with calf thymus DNA and producing a DNA standard serial dilution from 0-10 $\mu \mathrm{g}$ DNA $/ \mathrm{mL}$. The assay was prepared at a dilution of 1:1000 with $10 \%$ assay buffer and water. $100 \mu \mathrm{L}$ of the lysates and standard dilution was transferred to a black 96 well plate and $100 \mu \mathrm{L}$ of the Hoechst dye assay was added. Fluorescence was measured using an excitation wavelength of $360 \mathrm{~nm}$ and an emission wavelength of $460 \mathrm{~nm}$ in a microplate reader (Fluoroskan Ascent FL, Thermo Labsystems, UK).

A Quantikine ${ }^{\circledR}$ ELISA kit was used to determine the amount of human vascular endothelial growth factor (VEGF) concentrations found in the cell supernatant. The assay was 
performed according to the manufacturer's instructions $(R \& D$ Systems, UK) using $200 \mu \mathrm{L}$ of supernatant collected at each time point. A standard dilution series of VEGF was additionally produced ranging from $0 \mathrm{pg} / \mathrm{mL}$ to $1000 \mathrm{pg} \mathrm{mL}$ ${ }^{1}$. The optical density was measured with a microplate reader (BioTek, Instruments) set to $450 \mathrm{~nm}$ and correction wavelength $562 \mathrm{~nm}$.
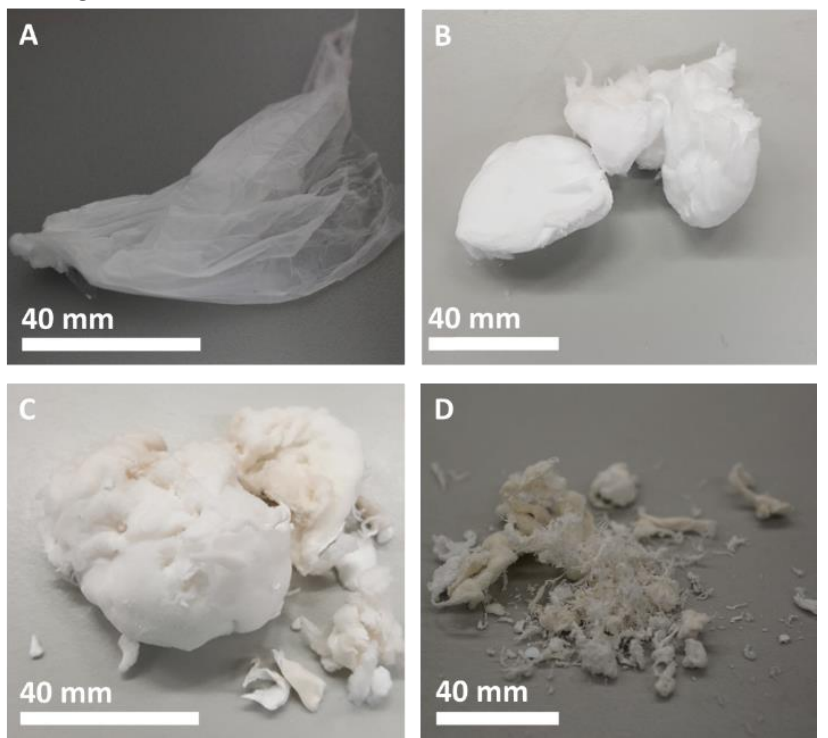

Figure 1. (A-D) Photographs showing the morphology of 70S30C sol electrospun at different relative humidity values (A) $27 \%$, , B) $35 \%$, ,C) $55 \%$ and (D) $65 \%$.

Metabolic activity was determined using an AlamarBlue assay according to manufacturer instructions (R\&D Systems, UK) study, twelve repeats were used for each sample, the tDNA and VEGF ELISA used nine repeats over two experimental repeats.

The statistical significance of the results was compared using a Kruskal-Wallis test followed by Dunn's Multiple Comparison was used to detect significance of each composition with respect to DMEM at each time point $(* \mathrm{P}<$ $0.05, * * \mathrm{P}<0.01, * * * \mathrm{P}<0.001, * * * * \mathrm{P}<0.0001)$.

\section{Results and discussion}

\subsection{Processing windows and fibre morphology}

To create the 3D cotton-wool-like fibrous structure, sols were prepared according to (Table 1), and equal amounts of binder and sol were mixed to fill a $10 \mathrm{~mL}$ syringe for electrospinning. The selected viscosity of the 70S30C sol/binder mixture was $0.069 \pm 0.025$ Pa.s.

Viscosities below $0.05 \mathrm{~Pa}$.s prevented the formation of fibres, resulting in sol spraying from the end of the needle. Viscosities greater than 0.6 Pa.s failed to electrospin. The inclusion of the binder to obtain the desired viscosity range made the successful electrospinning of the sol and formation of a fibremat easily repeatable.

The 70 S30C/binder sol was electrospun at a range of relative humidity values (Figure 1). At 27\% relative humidity, a 2D fibremat structure was produced (Figure $1 \mathrm{~A}$ ). Increasing the relative humidity to $35 \%$ (Figure 1B) and 55\% relative)
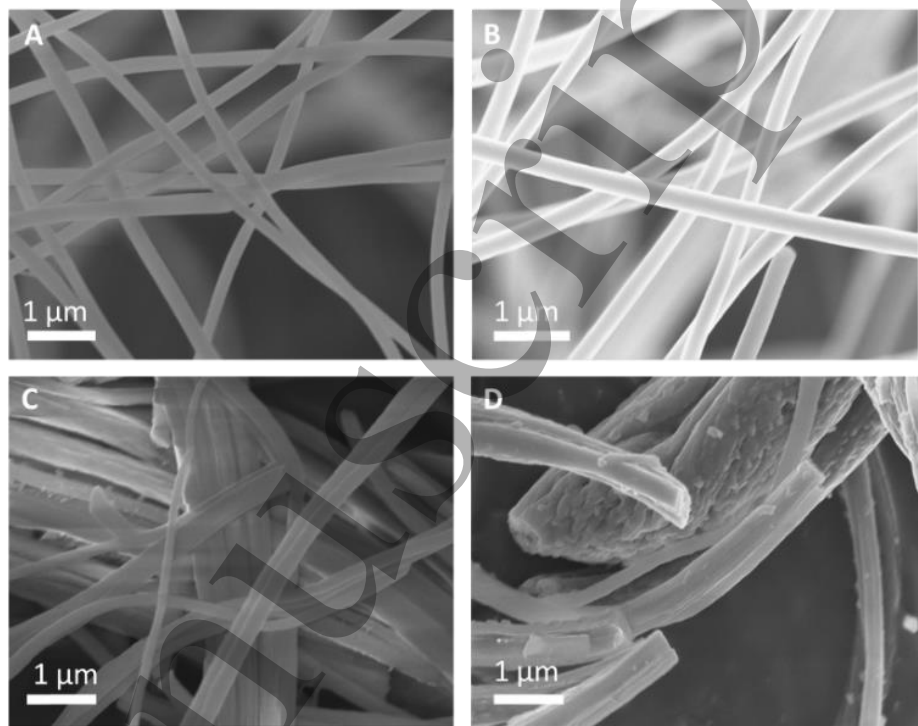

Figure 2. SEM images of the morphology of 70S30C electrospun samples. The relative humidity in each of the samples (A), (B), (C) and (D) was found to be (A) $27 \%$, (B) $35 \%$, (C) $55 \%$ and (D) $65 \%$.

humidity (Figure 1C) produced a structure with a 3D cotton-wool-like appearance, similar to that attained by Poologasundarampillai et al. [25]. At a relative humidity of $65 \%$ (Figure 1D), the bioactive glass also had an appearance similar to that of a 3D structure. SEM images (Figure 2) of the fibre morphology present the fibres electrospun at the same relative humidity values. Fibres electrospun at $27 \%$ relative humidity (Figure 2A) were found to be long, uniform and straight without the presence of beads. Fibres electrospun at $35 \%$ and $55 \%$ relative humidity (Figure $2 \mathrm{~B}$ and $2 \mathrm{C}$ ) were much more undulating, creating the appearance of the $3 \mathrm{D}$ structure observed in Figure 1B and 1C. Figure 2D showed fibres which are non-uniform in length and diameter and beading was observed in the fibres.

The fibres electrospun at 55\% and at $65 \%$ humidity (Figure $2 \mathrm{C}$ and 2D) contained fragments of broken fibre attached to the longer, formed fibres. This was much more prevalent in the structure electrospun at $65 \%$ humidity. Xie et al. [43] suggested that, for collagen fibres, short fibre lengths, such as those in Figure 2C and 2D, among other factors such as high fibre stiffness in collagen gels, prevented the spreading and proliferation of human mesenchymal stem cells (hMSCs). The small fragments of fibres are created by capillary instability, which converts a cylindrical jet into droplets of sol, which solidify as beads when they reach the collector [36]. 
3

4

5

6

7

8

9
Reneker et al. [36] reported them as a bead-on-a-string structure in polymers [44] due to capillary instability. In this case the beads were spaced at similar, repeating distances and patterns along the length of the fibres. uniform fibres, similar to 70 S30C fibres produced at $27 \%$ relative humidity (Figure $3 \mathrm{~A}$ ).

The $100 \mathrm{~S}$ structures electrospun at $66 \%$ and $80 \%$ humidity
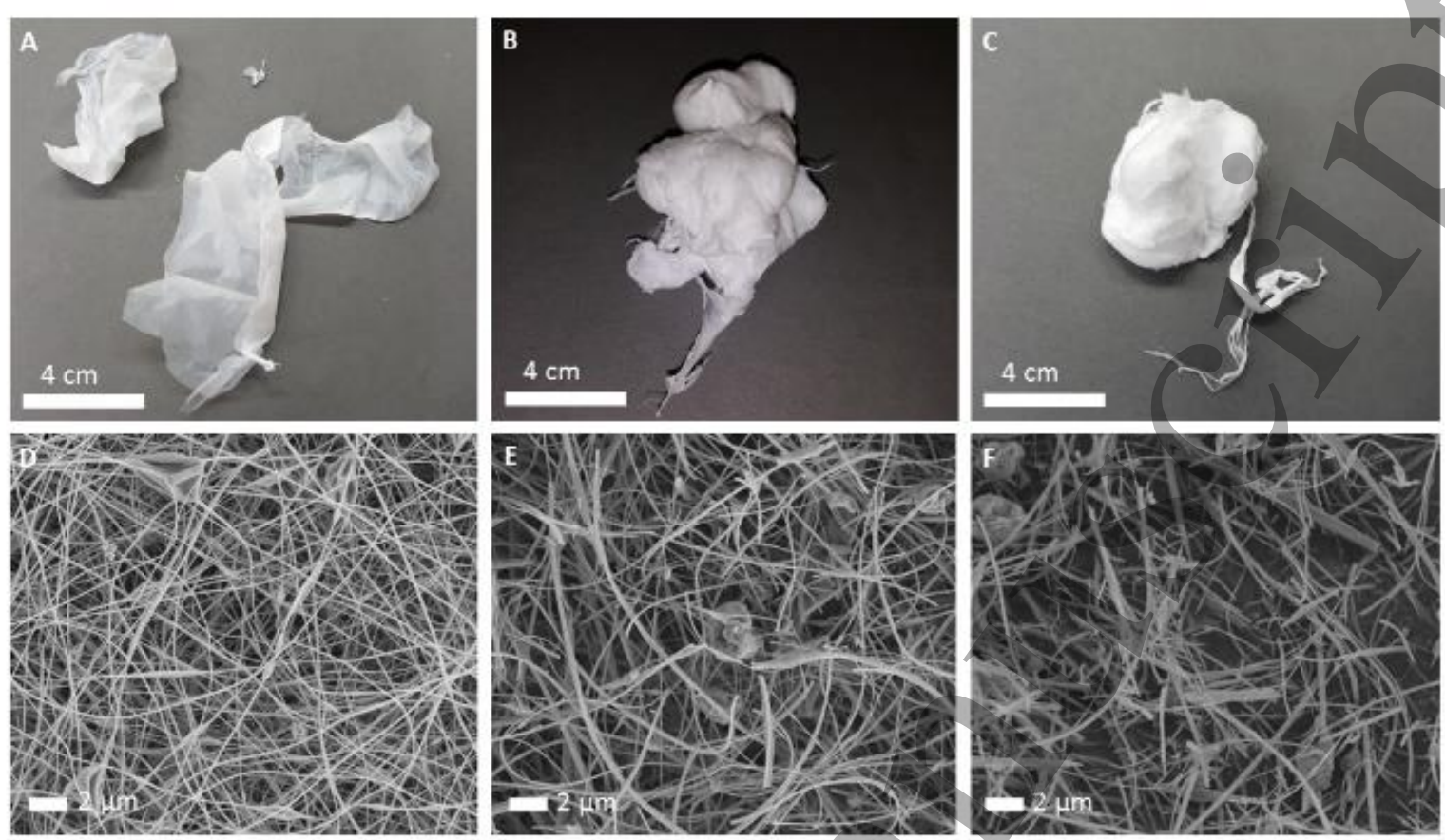

Figure 3. (A-C) Photographs showing the morphology of 100S (100 mol\% $\left.\mathrm{SiO}_{2}\right)$ electrospun cotton wool at relative humidity values of (A) $36 \%$, (B) $66 \%$ and (C) $80 \%$. (D-F): SEM images show the fibre morphology at relative humidity values of (D) $33 \%$ (E) $66 \%$ and (F) $80 \%$.

appearance of a 3D cotton-wool-like structure despite no presence of $\mathrm{Ca}^{2+}$ in the sol. The corresponding SEM images however show differences between the fibres of the three samples: the 100S sample electrospun at $36 \%$ relative humidity (Figure 3D) had long, uniform, undulating fibres with the presence of some small beads. The $100 \mathrm{~S}$ sample

The fragments formed by electrospinning the 70S30C and $100 \mathrm{~S}$ sol-gel solutions, at relative humidity values above $55 \%$, did not have this appearance. The beads here resulted from the sputtering of the sol-gel while electrospinning, resulting in the formation of bead-like drops of solid sol. Our working hypothesis is that the cotton wool-like entangled fibres are preferable for wound healing applications.

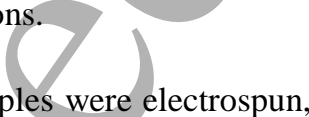

When the 100S bioactive glass samples were electrospun, changes in the fibre morphology were identified (Figure 3). The 100S sample electrospun at a relative humidity of $36 \%$ (Figure 3A) had the appearance of a 2D, fibremat-like structure, and SEM images show (Figure 3D) straight and electrospun at $66 \%$ (Figure 3E) had long, heterogeneous fibres with beads. The fibres electrospun at $80 \%$ relative humidity (Figure 3F) were short, with a large quantity of beads and some presence of whiskers.

Sol-gel bioactive glass compositions were electrospun with different quantities of $\mathrm{Ca}^{2+}$ added to produce a range of different compositions. Figure 4 shows variations in the morphology of the 60S40C, 70S30C, 80S20C, 90S10C and $100 \mathrm{~S}$ bioactive glass compositions samples electrospun at similar values of relative humidity $(30-40 \%)$. While this result confirms that the presence of calcium nitrate in the sol-gel composition impacts the 3D morphology [25], we show that

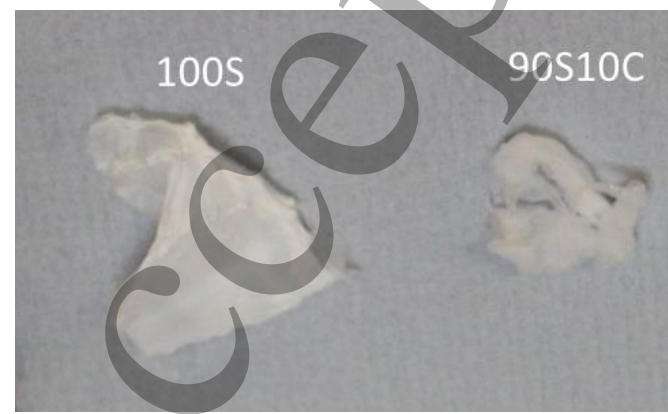

$80520 C$ $70530 \mathrm{C}$ $60540 \mathrm{C}$
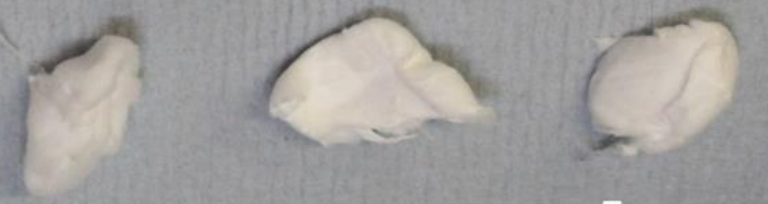

$5 \mathrm{~cm}$ 
the relative humidity additionally determines the $2 \mathrm{D}$ or $3 \mathrm{D}$ nature of fibremat produced, even without calcium (Figure 3).

Figure 4. Photographs showing the morphology of bioactive glass fibres: $100 \mathrm{~S}, 90 \mathrm{~S} 10 \mathrm{C}, 80 \mathrm{~S} 20 \mathrm{C}, 70 \mathrm{~S} 30 \mathrm{C}$ and $60 \mathrm{~S} 40 \mathrm{C}$ electrospun at a relative humidity of $30-40 \%$.

\subsection{Chemical composition}

\begin{tabular}{ccccc}
\hline \multirow{2}{*}{ Sample } & \multicolumn{2}{c}{ Composition } & $\begin{array}{c}\text { Fibre } \\
\text { Surface Area } \\
{\left[\mathrm{m}^{2} \mathrm{~g}^{-1}\right]}\end{array}$ & $\begin{array}{c}\text { Diameter } \\
{[\mu \mathrm{m}]}\end{array}$ \\
\hline 70S30C & $68.1 \pm 0.2$ & $31.9 \pm 0.2$ & 43.1 & $0.34 \pm 0.11$ \\
80S20C & $77.4 \pm 0.2$ & $22.6 \pm 0.2$ & 40.0 & $0.21 \pm 0.02$ \\
\hline
\end{tabular}

XRD diffraction patterns with amorphous halos without peaks. The peaks formed herein could be attributed to the higher surface area due to the fine fibres or the electrospinning process itself, with the electric field provoking a heterogeneous distribution of $\mathrm{Ca}^{2+}$ within the silicate.

60S40C, 70S30C, 80S20C and 90S10C powders, made without electrospinning, are all previously reported to form carbonate apatite layer formation following immersion in SBF [46]. For practical experimental reasons, certain compositions were disregarded at this point. The relative humidity range that needed for electrospinning 90S10C sol to produce a 3D cotton-wool-like, structure was difficult to achieve. The 60S40C sample was also dismissed due to the presence of peaks in the XRD indicating calcium

Table 2. Electrospun sol-gel bioactive glass composition (from ICP), fibre diameter (from SEM) and specific surface area (determined by $\mathrm{N}_{2}$ sorption).

FTIR spectra were collected for each of the compositions. A main Si-O stretch vibration band between 1000 and 1070 $\mathrm{cm}^{-1}$ was present in each of the samples (Figure 5A). There was no evidence of un-hydrolysed TEOS in any of the spectra, which indicates that all the hydrolysis and condensation reactions had taken place and that residues from the precursor reagents and binder were removed through heating. The FTIR spectra for 100S, 90S10C, 80S20C, 70S30C and 60S40C compositions show bands corresponding to $\mathrm{Si}-\mathrm{O}$ at 1058.73 , $1053.91,1038.48,1027.39$ and $1037.03 \mathrm{~cm}^{-1}$ and for $\mathrm{Si}-\mathrm{OH}$ at $801.67,801.28,796.56,787.78$ and $942.54 \mathrm{~cm}^{-1}$. An increase in the calcium content of bioactive glasses corresponded to a shift in wavenumber of the bands attributed to $\mathrm{Si}-\mathrm{O}$ stretching [45]. The 60S40C and 70S30C spectra show two bands (1500 and $1410 \mathrm{~cm}^{-1}$ ) which can be attributed to $\mathrm{CO}_{3}^{2-}$ groups [46]. This band was more intense in samples with higher calcium content, where the increased calcium content was responsible for the presence of carbonate, attributed to a carbonation process of the material due to the atmospheric $\mathrm{CO}_{2}$ and moisture present [47].

XRD patterns (Figure 5B) of the electrospun sol-gel derived compositions of the 60S40C, 70S30C, 80S20C, 90S10C and 100S compositions all showed amorphous silica halos. Multiple peaks at $29^{\circ}, 32^{\circ}, 34^{\circ}, 37^{\circ}$ and $48^{\circ}$ were present in the 60S40C composition, which can be attributed to crystalline phases of calcium silicates, such as Wollastonite. PANalytical X'Pert HighScore peak fitting software identified that these peaks could be either anorthic (00-014-0693) or orthorhombic (00-024-0234) calcium silicates. The 60S40C fibres therefore had inhomogeneous structures but these peaks were not found for samples with lower calcium content. Martinez et al. [46] showed sol-gel derived 60S40C discs gave silicates (Figure 5B). Therefore further studies were carried out on the 70S30C and 80S20C compositions only.

The measured compositions of the 80S20C and 70S30C bioactive glass samples were very similar to the nominal compositions (Table 2). The mean fibre diameter of the 80S20C and 70S30C were $0.21 \pm 0.02 \mu \mathrm{m}$ and $0.34 \pm 0.11 \mu \mathrm{m}$ respectively. Nitrogen sorption was carried out to test the specific surface areas (BET method) of the 70S30C and 80S20C fibres (Table 2), which were $43.1 \mathrm{~m}^{2} \mathrm{~g}^{-1}$ and $40.0 \mathrm{~m}^{2}$ $\mathrm{g}^{-1}$ respectively.

Data obtained by ${ }^{29} \mathrm{Si}$ MAS NMR enabled the identification of $\mathrm{Q}^{\mathrm{n}}$ species defining the glass network, where $\mathrm{Q}^{\mathrm{n}}$ corresponds to the structural species $\mathrm{Si}(\mathrm{OSi})_{\mathrm{n}} \mathrm{O}(\mathrm{R})_{4-\mathrm{n}}$ (with $\mathrm{R}$ representing either $\mathrm{Ca}$ or $\mathrm{H}$ in the case of these glass formulations). The 70S30C and 80S20C glass compositions prepared at relative humidity values between $30-45 \%$ electrospinning conditions were compared, with both compositions exhibiting typical ${ }^{29} \mathrm{Si}$ chemical shifts averaging at $-83.3,-92.3,-100.3$ and $-109.9 \mathrm{ppm}$ which were assigned to $\mathrm{Q}^{1}, \mathrm{Q}^{2}, \mathrm{Q}^{3}$ and $\mathrm{Q}^{4}$ units, respectively (Table 3).

The broad ${ }^{29} \mathrm{Si}$ resonances characterising these $\mathrm{Q}^{\mathrm{n}}$ species in Supplementary Figure S1 (SF1) are indicative of large structural distributions and disorder influencing the $\mathrm{Si}$ positions within the network. This observation is consistent with previous work by Lin et al. [48], who demonstrated that the ${ }^{29} \mathrm{Si}$ resonances corresponding to $\mathrm{Q}^{\mathrm{n}}$ species in $70 \mathrm{~S} 30 \mathrm{C}$ glasses 


\begin{tabular}{|c|c|c|c|c|c|c|c|c|c|c|}
\hline \multirow[b]{2}{*}{ Sample } & \multicolumn{2}{|c|}{$\mathrm{Q}_{1}$} & \multicolumn{2}{|c|}{$\mathrm{Q}_{2}$} & \multicolumn{2}{|c|}{$Q_{3}$} & \multicolumn{2}{|c|}{$\mathrm{Q}_{4}$} & \multirow[b]{2}{*}{ Dc [\%] } & \multirow[b]{2}{*}{ Connectivity } \\
\hline & $\begin{array}{c}\delta \\
{[\mathrm{ppm}]}\end{array}$ & I [\%] & $\begin{array}{c}\delta \\
{[\mathrm{ppm}]}\end{array}$ & I [\%] & $\begin{array}{c}\delta \\
{[\mathrm{ppm}]}\end{array}$ & I [\%] & $\begin{array}{c}\delta \\
{[\mathrm{ppm}]}\end{array}$ & I [\%] & & \\
\hline $70 S 30 \mathrm{C}$ & -84.42 & 10.00 & -93.10 & 12.10 & -100.56 & 17.90 & -109.66 & 60.00 & 81.98 & 3.28 \\
\hline $80 S 20 C$ & -82.18 & 4.60 & -91.44 & 16.70 & -100.02 & 23.60 & -110.15 & 55.00 & 82.20 & 3.29 \\
\hline
\end{tabular}

heated to $700{ }^{\circ} \mathrm{C}$ were also influenced by large structural distributions and disorder in the $\mathrm{SiO}_{2}-\mathrm{CaO}$ glass network [48].

Table 3. Relative $\mathrm{Q}^{\mathrm{n}}$ unit distribution in the glass structure (from solid-state ${ }^{29} \mathrm{Si}$ MAS-NMR) and degree of condensation of the 70S30C and 80S20C bioactive glass samples.

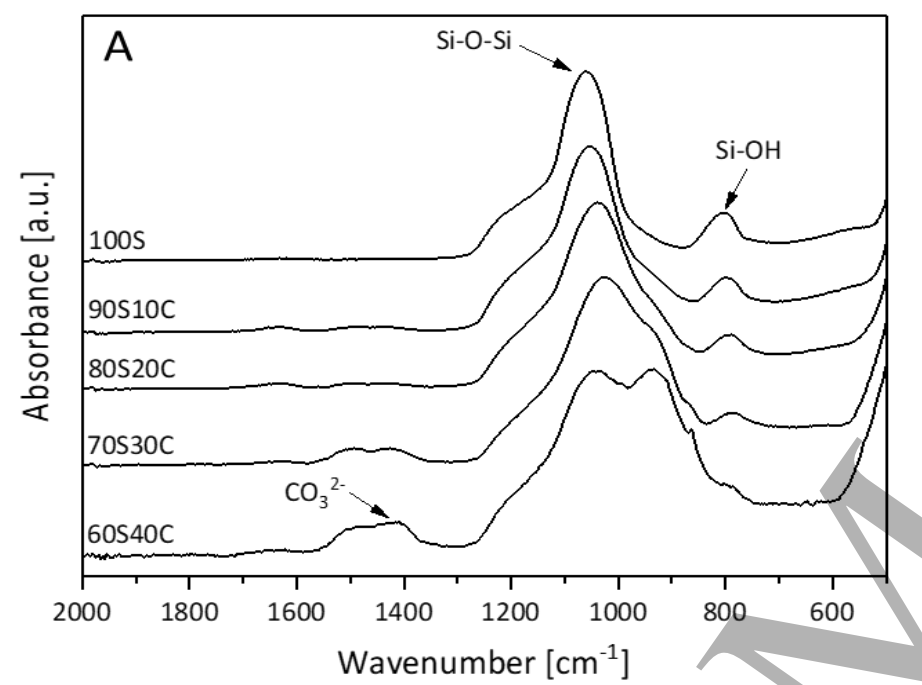

Figure 5. Characterisation of electrospun sol-gel glasses: (A) FTIR spectra; (B) XRD patterns.
The electrospun 70S30C and 80S20C samples were found to have a larger proportion $\mathrm{Q}^{4}$ (both $\sim 82 \%$ ) and a much smaller percentages of $\mathrm{Q}^{1}$ and $\mathrm{Q}^{2}$ species in comparison to conventionally prepared sol-gel 70S30C glass [48]. The degree of condensation, $\mathrm{D}_{\mathrm{c}}$, was calculated by equation [49]:

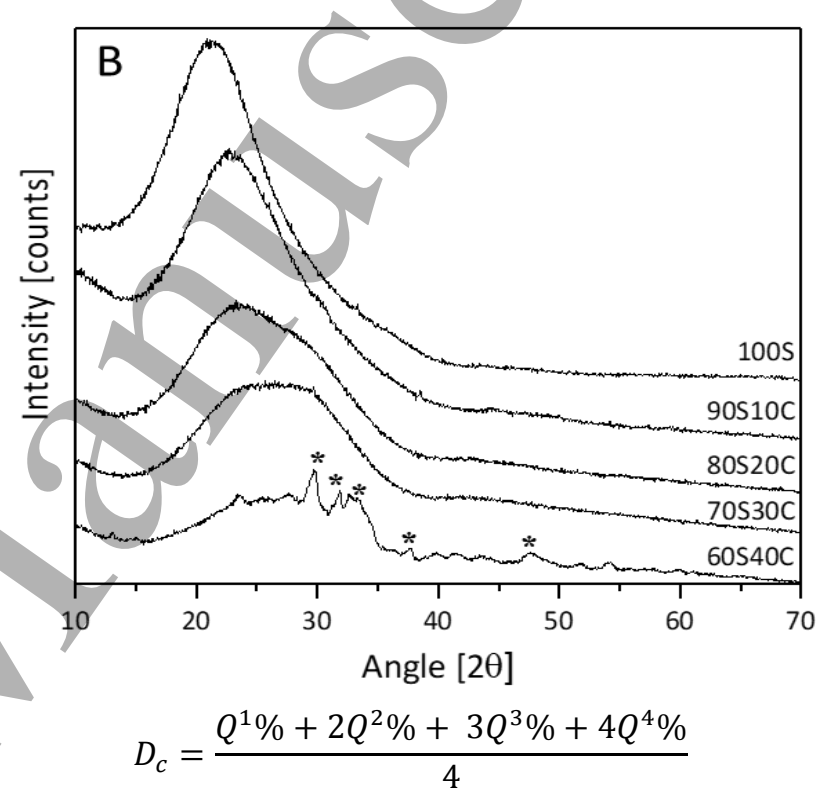

$\mathrm{D}_{\mathrm{c}}$ of the 70S30C and 80S20C glass compositions were similar (Table 3), and much higher than that found in the conventional Ca-containing 70S30C glasses [48], which exhibited a network connectivity of 2.62 and a $D_{c}$ of $65 \%$. The pre-stabilisation network connectivity of their glass composition (only dried at $130^{\circ} \mathrm{C}$ ) was calculated to be 3.65 with a $\mathrm{D}_{\mathrm{c}}$ of $91.3 \%$. Ca was not incorporated into the network as a network modifier until a stabilisation temperature of $\sim 450$ ${ }^{\circ} \mathrm{C}$ was reached [48]. Poologasundarampillai et al. calculated the degree of condensation in their unstabilised (only dried) 70S30C fibres to be higher $\sim 90 \%$, suggesting that the calcium was not incorporated in the silica network [28].

While 70S30C and 80S20C fibres prepared herein had a reduced network connectivity and $\mathrm{D}_{\mathrm{c}}$ compared with the 70S30C fibres of Poologasundarampillai et al. [25], they were not as low as those exhibited in monolithic sol-gel derived 70S30C composition. 

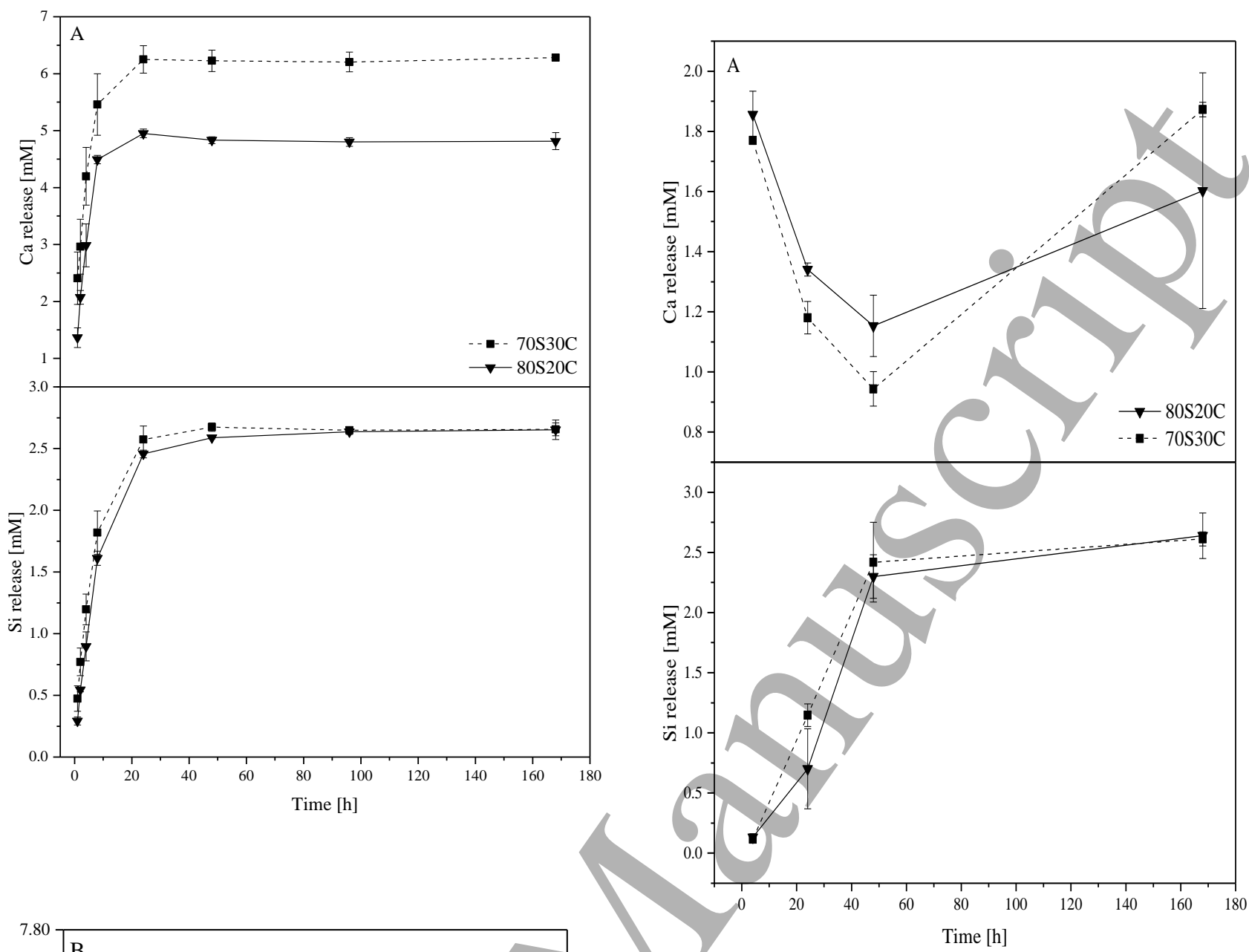

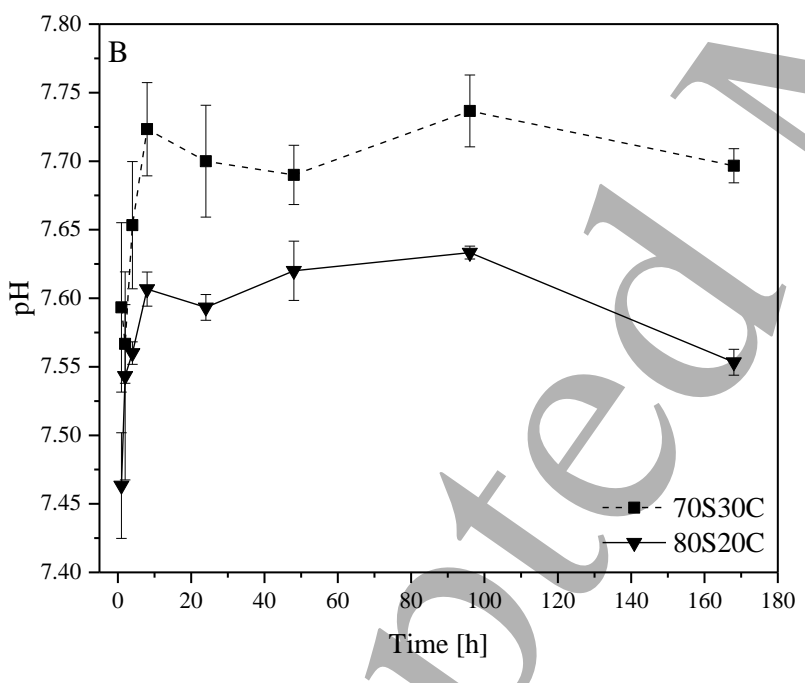

Figure 6. (A) Dissolution profiles (ICP-OES) of TRIS containing electrospun sol-gel glass samples as a function of time, (B) $\mathrm{pH}$ profile of the TRIS during glass dissolution.

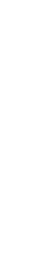

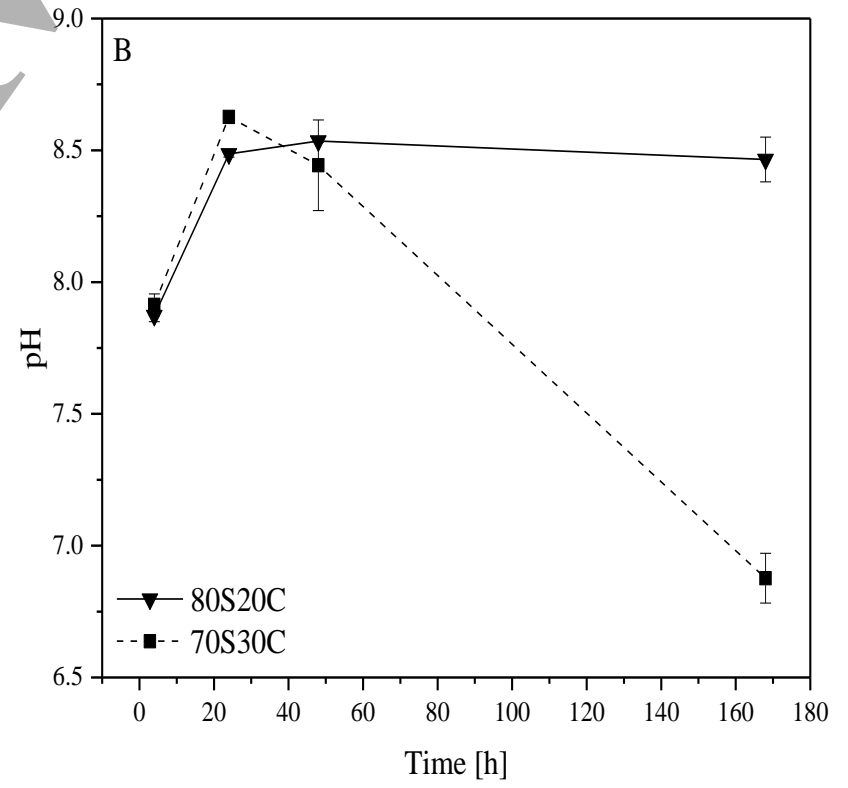

Figure 7. (A) Dissolution profiles (ICP-OES) of electrospun sol-gel glasses in DMEM at time points of $4 \mathrm{~h}, 1$ day, 3 day and 7 day, (B) $\mathrm{pH}$ profile of DMEM during glass dissolution. 

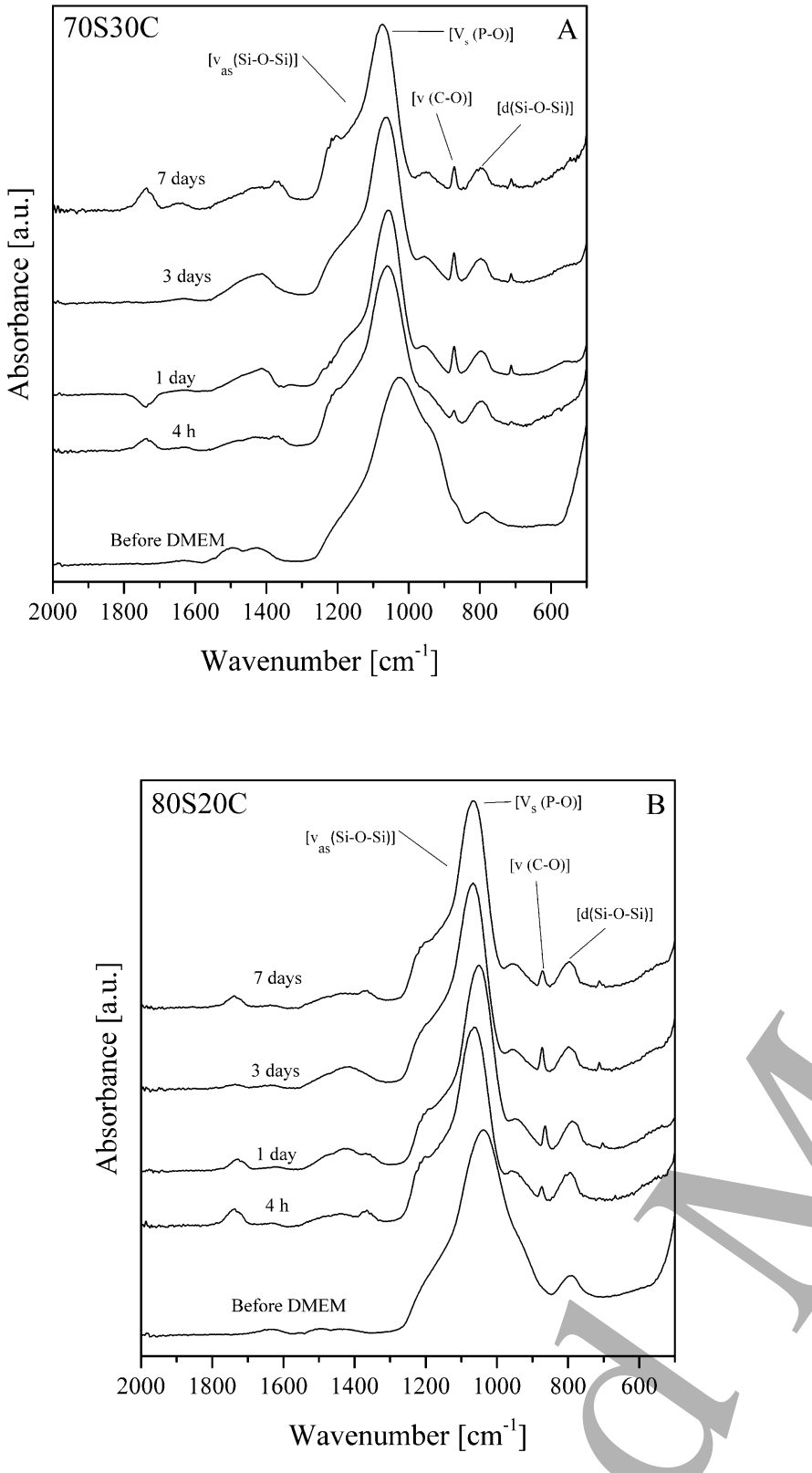

Figure 8. FTIR spectra of $70 \mathrm{~S} 30 \mathrm{C}$ (A) and 80 S20C (B) electrospun sol-gel glasses before and after being soaked in DMEM for 7 days.

\subsection{Dissolution studies}

A high proportion of the calcium ions and soluble silica were released to the surrounding solution within $50 \mathrm{~h}$ of soaking in TRIS (Figure 6A). The concentration of soluble silica was similar between the two compositions but the 70S30C glass produced a greater concentration of calcium ions compared to the 80S30C composition. This was expected as the 70S30C contained more calcium, and both of the glasses induced a pH change in TRIS (Figure 6B). After $168 \mathrm{~h}$, TRIS containing $70 \mathrm{~S} 30 \mathrm{C}$ had a $\mathrm{pH}$ of $\sim 7.70$ and that containing $80 \mathrm{~S} 20 \mathrm{C}$ was 7.55 . The $\mathrm{pH}$ increased [48],[49] during bioactive glass degradation as result of the exchange between modifier cations, such as $\mathrm{Ca}^{2+}$, from the glass and protons from the dissolution media [50]. During dissolution studies, changes in the $\mathrm{pH}$ therefore provide indication of the amount of ion exchange occurring [51].

The dissolution study in DMEM (Figure 7A) shows similar concentration profiles for the two compositions for silicon and for calcium. Si levels were similar to what they were for the TRIS immersion, however the Ca decreased for the first three days, before increasing again by day seven. Ca eoncentration at day 7 for the 80 S20C sample was $\sim 1.60 \mathrm{mM}$ and KuleszMartin et al. [52] showed that dermal fibroblasts grew best at concentrations of $1.4 \mathrm{mM} \mathrm{Ca}^{2+}$. The dissolution in DMEM (Figure 7) shows that the 70S30C and 80S20C compositions were nearest this value at the $4 \mathrm{~h}$ time point and therefore dissolution product at this time point was determined to be the most appropriate for use in the cellular cell studies.

The decrease in concentration of calcium ions in SBF is characteristic of the species being involved in both the dissolution and precipitation (such as hydroxycarbonate apatite formation) [53]. Figure 7B shows a higher $\mathrm{pH}$ value for both-in DMEM, at all time points, compared with that shown in TRIS (Figure 5B).

FTIR spectra of the samples after seven days immersion (Figure 8) identified an additional band at $\sim 872 \mathrm{~cm}^{-1}$, which was attributed to the $\mathrm{C}-\mathrm{O}$ stretching peak of the $\mathrm{CO}_{2}{ }^{3-}$ group typically associated with the formation of hydroxycarbonate apatite on glasses [54]. Other bands associated with $\mathrm{C}-\mathrm{O}$ at $\sim 1400 \mathrm{~cm}^{-1}$ were however not identified [55].

XRD patterns (Figure 9) for the 70S30C fibres contained peaks after $4 \mathrm{~h}$ in DMEM. While some of these peaks could be attributed to hydroxyapatite, which displays peaks at $\sim 28^{\circ}$, $\sim 32^{\circ}, \sim 39^{\circ}, \sim 43^{\circ}$ and $\sim 49^{\circ}$, hydroxyapatite also has additional peaks which were not found in the XRD pattern presented in Figure 9. Crucially, the primary peak associated with hydroxyapatite $\left(2 \theta=\sim 32^{\circ}\right)[56]$ was not present in the patterns produced from this study. Peak fitting software (PANalytical X'Pert HighScore Plus) and comparisons in literature showed that the pattern of peaks fitted most loosely with Calcite [56]. 


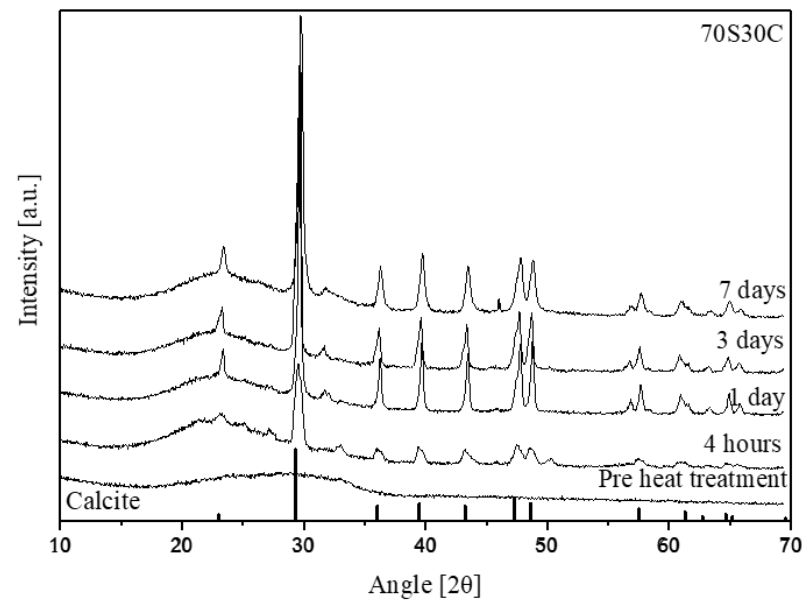

Figure 9. XRD patterns of 70S30C and 80S20C electrospun sol-gel glasses before and after being immersed in DMEM for 7 days. 70S30C and 80S20C patterns contain peaks attributed to calcite (ICDD reference 00-005-0586). The 80S20C pattern additionally shows the presence of halite $(\mathrm{NaCl}, \mathrm{ICDD}$ reference of 00-001-0994).

These peaks were identified at 4 h, 1 day, 3 days and 7 days immersion of 70S30C fibres in DMEM, indicating the formation of calcite happened very quickly after immersion. The XRD patterns for 80S20C shows a similar array of peaks at each of the $4 \mathrm{~h}, 1$ day 3 day and 7 day time points, indicating that the formation of calcite was similar. The day 7 pattern of the $80 \mathrm{~S} 20 \mathrm{C}$ sample additionally showed peaks at $33^{\circ}, 46^{\circ}$ and $56^{\circ}$ which were attributed to halite (cubic sodium chloride).

\subsection{Cell studies}

Angiogenesis, which is critical for tissue regeneration, involves the sprouting of endothelial cells from pre-existing vessels, a process which is regulated by the local tissue balance of inhibitory molecules (such as thrombospondin), including growth factors, most notably VEGF.

A large number of in vivo studies have demonstrated that VEGF plays a central role in angiogenesis, although studies on the in vivo induction of angiogenesis by bioactive glasses are rare, such as Midha et al. [57]. In vitro studies carried out by Day et al. showed that dissolution products from bioactive glasses stimulate fibroblasts to secrete VEGF [19].

In addition to release of ions, glass particle size in silicate bioactive glasses is also as an important determinant of cellular growth factor production in vitro, as smaller particles (1-2 $\mathrm{mm})$ are more effective than bigger particles $(2-3.15 \mathrm{~mm})$ for inducing VEGF secretion by human CD-18CO fibroblasts [58]. An aim herein was to determine whether the increased

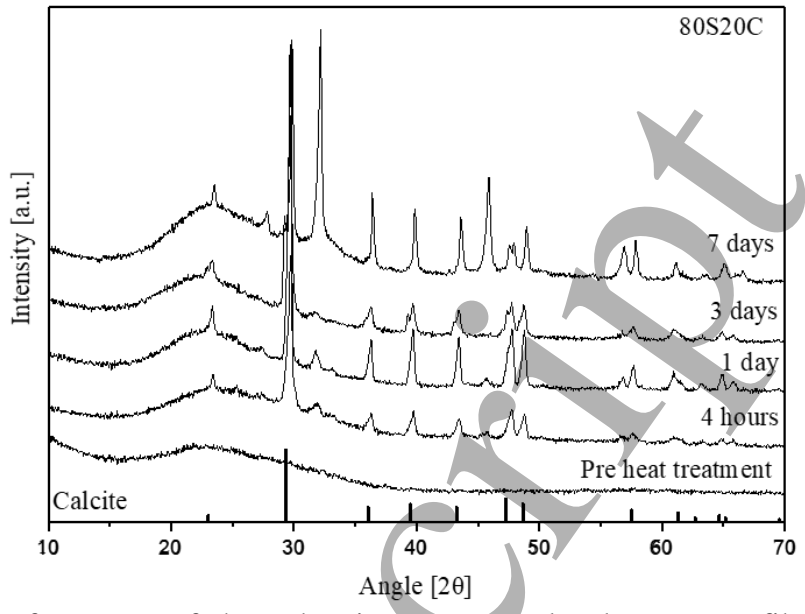

surface area of the sub-micrometre scale electrospun fibres induced greater growth factor expression.

The AlamarBlue $($ assay (Figure 10A) revealed no significant differences in metabolic activity between $\mathrm{Si}$ or vehicle only DMEM control cultures and those exposed to 70S30C and 80S20C bioactive glass dissolution products at days 1,3 or 7 .

The tDNA values from control samples in cultures from CD-18CO fibroblast cells were consistent with linear cell growth on days $1-3$ and exponential growth by day 7 . Cultures exposed to either 70 S30C or 80 S20C dissolution products/were not significantly different from those of vehicle-only (or Si control) cultures at day 1 (Figure 10B) when compared with the pre-exposed tDNA at day 0. At day 3 , tDNA values were significantly higher in 80S20C samples than for vehicle only or Si controls (*p $<0.05)$. By day 7 , the tDNA content from both vehicle-control and Si-control cultures was significantly higher than that of cultures exposed 

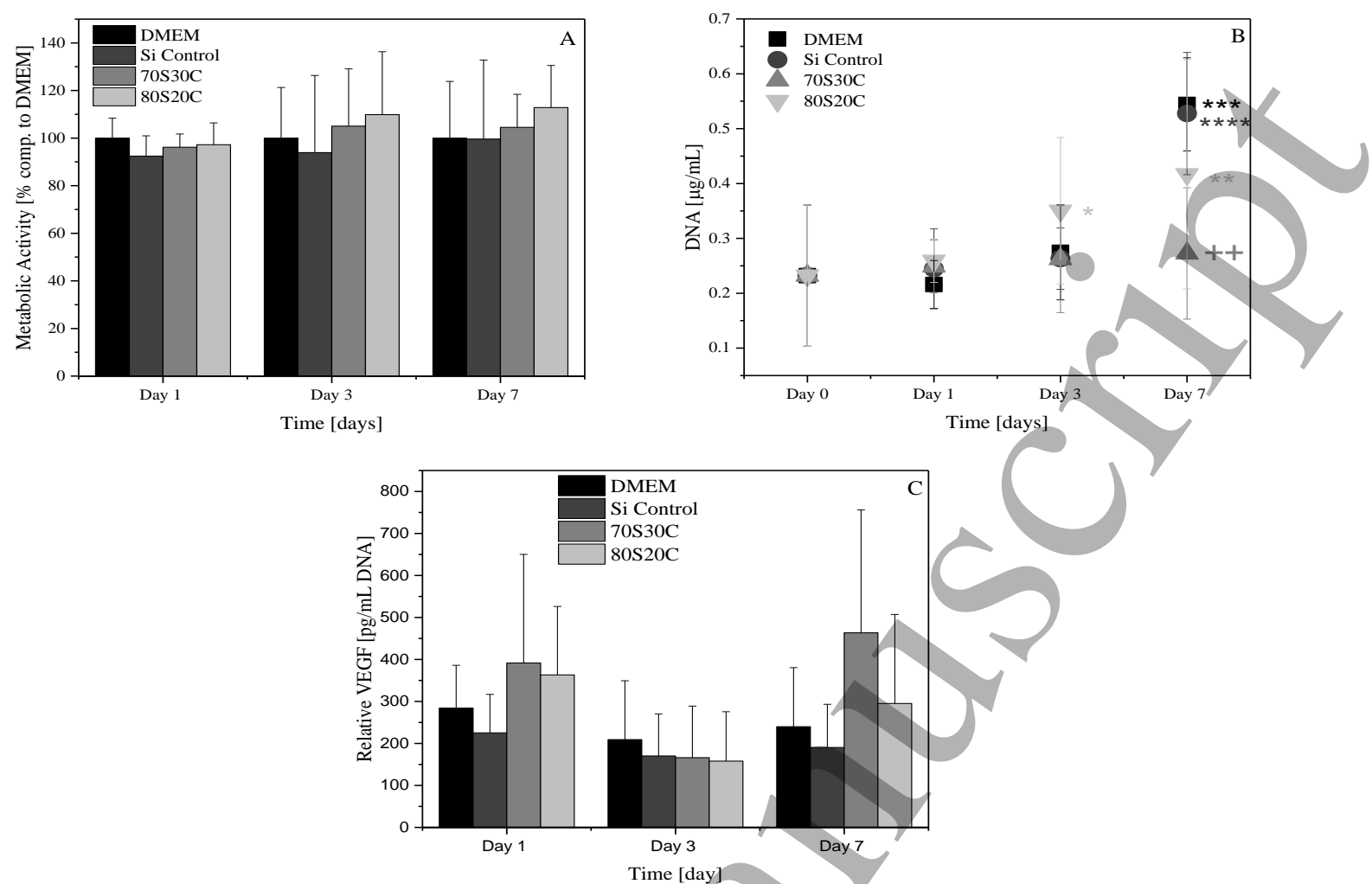

to either $80 \mathrm{~S} 20 \mathrm{C}(* \mathrm{p}<0.05)$ or $70 \mathrm{~S} 30 \mathrm{C}$ dissolution products, consistent with an inhibitory effect on cell growth.

Statistical analysis was also carried out to compare each of the conditions against the DMEM control vehicle condition at each time point. Day 1 and day 7 showed no significant difference in any of the conditions compared with the DMEM control vehicle. At day 7, the 70S30C condition had a significantly lower tDNA compared to the DMEM control sample. This reduction in significance indicates that the 70S30C composition inhibited the tDNA of the cell cultures by day 7 of exposure.

In order to compare absolute VEGF levels across cultures exposed to different bioactive glass compositions, we normalized VEGF values in each culture to tDNA content for that sample (Fig. 10C). There were no significant differences in the amount of VEGF/pg DNA between any of the sample conditions (NS; $\mathrm{p}<0.05)$ or between similar samples across time points (NS; $p>0.05$ ). This suggests that the presence of the $3 \mathrm{D}$ cotton-wool-like bioactive glass compositions did not inhibit the production of VEGF. Previous studies show that the presence of certain ions can increase VEGF production in a variety of cell types [59]. Therefore, the compositional flexibility offered by the sol-gel derived, bioactive glass 3D structure could provide use as a vehicle to deliver additional therapeutic ions into the wound bed in a structure which mimics that of the extracellular matrix. These additional ions may be needed to provoke a true angiogenic effect.
Figure 10. The $70 \mathrm{~S} 30 \mathrm{C}$ and $80 \mathrm{~S} 20 \mathrm{C}$ bioactive glass fiber compositions did not affect metabolic activity on CD-18CO cultures compared to controls over a seven day study. (A) Metabolic activity [\% comp. DMEM Control] of HDF cultures exposed to DMEM (DMEM, FBS and P/S) containing the dissolution product of bioactive glasses 70S30C and 80S20C, the Si and DMEM control samples after 1 day, 3 day and 7 day. A Kruskal-Wallis test followed by Dunn's Multiple Comparison were used to detect statistical significance of the samples. Metabolic activity of samples were normalized to respective DMEM controls at each time point $(\mathrm{n}=12, \mathrm{NS}$; * $\mathrm{P}<0.05)$; (B) Proliferation $[\mu \mathrm{g} / \mathrm{mL}]$ of HDF cultures exposed to DMEM containing the dissolution product of bioactive glass glasses 70S30C and 80S20C, the Si control samples and DMEM after 1 day, 3 day and 7 day. A Kruskal-Wallis test followed by Dunn's Multiple Comparison was used to detect statistical significance of each composition with respect to the pre-exposed tDNA at day $0(\mathrm{n}=9, * \mathrm{P}<$ $0.05, * * \mathrm{P}<0.01, * * * \mathrm{P}<0.001, * * * * \mathrm{P}<0.0001)$. A second Krustal-Wallis test followed by Dunn's Multiple Comparison was used to detect statistical significance of each composition with respect to the result of the DMEM at each time point. $(\mathrm{n}=9,+\mathrm{P}<0.05,++\mathrm{P}<0.01,+++\mathrm{P}<0.001,++++\mathrm{P}<$ $0.0001)$; (C) Normalised VEGF production $[\mathrm{pg} / \mu \mathrm{L}]$ of HDF cultures exposed to DMEM containing the dissolution product of bioactive glass glasses 70S30C and 80S20C, the Si control samples and DMEM after 1 day, 3 day and 7 day normalized 
to each sample's tDNA $[\mu \mathrm{g} / \mathrm{mL}]$ value. A Kruskal-Wallis test followed by Dunn's Multiple Comparison was used to detect statistical significance of each composition with respect to DMEM at each time point.

\section{Conclusions}

An inorganic sol-gel derived material was electrospun from its sol, producing 3D cotton-wool-like structures with long and homogenous fibre diameters for use as a wound healing scaffold. The 3D cotton-wool-like morphology was formed not solely due to the calcium content of the sol, as previously thought, but was also dependent on the relative humidity in which it is electrospun. This meant that calcium-free silica sols could also be spun into 3D architectures. A humidity range for spinning each of the five-sol compositions into $3 \mathrm{D}$ architectures was identified. The 90S10C and 60S40C compositions were discarded due to laboratory humidity constraints and the presence of peaks in XRD scans. Two compositions (70S30C and 80S20C) were studied further to determine their suitability for use in wound healing applications. From ${ }^{29} \mathrm{Si}$ MAS NMR data, electrospun 70S30C and $80 \mathrm{~S} 20 \mathrm{C}$ glass fibres had increased network connectivity in comparison conventional sol-gel derived 70S30C glasses. Studies in TRIS buffer and DMEM both lead to the rapid release of silicon and calcium. Cell studies using a CD-18CO cell line were carried out on the dissolution product of 80S20C and 70S30C samples and were both found not to inhibit the expression of VEGF from CD-18CO cells over a period of seven days.

\section{Acknowledgements}

The authors would like to thank EPSRC for the funding through the CDT in Advanced Characterisation of Materials (CDT-ACM) (EP/L015277/1). JVH acknowledges support for the solid state NMR instrumentation at Warwick used in this research which was funded by EPSRC and the University of Warwick, with additional partial funding being provided through the Birmingham Science City AM1 and AM2 projects which were supported by Advantage West Midlands (AWM) and the European Regional Development Fund (ERDF). Raw data is available on request from rdmenquiries@imperial.ac.uk.

\section{References}

[1] Guest J et al 2015 Health economic burden that wounds impose on the National Health Service in the UK BMJ Open 5 12 1 1-8

[2] Sen C et al 2009 Human skin wounds: A major and snowballing threat to public health and the economy Wound Repair Regen $176763-771$
[3] Harper D, Young A, McNaught C 2014 The physiology of wound healing Surg $329445-450$

[4] Guo S, Dipietro L 2010 Factors affecting wound healing $J$. Dent. Res. 893 219-29

[5] Frykberg RG, Banks J 2015 Challenges in the Treatment of Chronic Wounds Adv. Wound Care 49 560-582

[6] Han G, Ceilley R 2017 Chronic Wound Healing: A Review of Current Management and Treatments Adv. Ther 343 599-610

[7] Bell E, Ehrlich H, Buttle D, Nakatsuji T 1981 Living tissue formed in vitro and accepted as skin-equivalent tissue of full thickness Science 2114486 1052-1054

[8] Bello Y, Falabella F 2002 The role of graftskin (Apligraf) in difficult-to-heal venous leg ulcers J. Wound Care 115 182-3

[9] Veves A, Falanga V, Armstrong D, Sabolinski M 2001 Graftskin, a human skin equivalent, is effective in the management of noninfected neuropathic diabetic foot ulcers: A prospective randomized multicenter clinical trial Diabetes Care, 242 290-295.

[10] Fagrell B, Jorneskog G 1999 Disturbed microvascular reactivity and shunting - A major cause for diabetic complications Vasc. Med 43 125-127.

[11] Jones JR 2013 Review of bioactive glass: From Hench to hybrids Acta Biomater $914457-4486$

[12] Jones JR et al 2016 Bioglass and Bioactive Glasses and Their Impact on Healthcare Int. J. Appl. Glas. Sci 74 423-434

[13] Wilson J et al 1981 Toxicology and biocompatibility of bioglass J Biomed Mater Res 156 805-17

[14] Hench LLet al 1971 Bonding mechanisms at the interface of ceramic prosthetic materials J. Biomater. Res. 56 117-141

[15] Hench LL et al 2015 Opening paper 2015 - Some comments on Bioglass: Four Eras of Discovery and Development Biomed Glas 1 1 1-11

[16] Hench LL et al 2006 The story of Bioglass J. Mater. Sci. Mater. Med 1711 967-978

[17] Rahaman M et al 2011 Bioactive glass in tissue engineering Acta Biomater 76 2355-2373

[18] Miguez-Pacheco L, Hench LL, Boccaccini AR 2014 Bioactive glasses beyond bone and teeth: emerging applications in contact with soft tissues Acta. Biomater 13 1-15

[19] Day RM 2005 Bioactive glass stimulates the secretion of angiogenic growth factors and angiogenesis in vitro Tissue Eng 11 5-6 768-777

[20] Sepulveda P, Jones JR, Hench LL 2001 Characterization of Melt-Derived 45S5 and sol-gel derived 58S bioactive glasses 2001 J Biomed Mater Res 58 734-740

[21] Li R, Clark A, Hench LL 1991 An investigation of bioactive glass powders by sol-gel processing J Appl Biomater 24 231-239

[22] Jung D, Day S 2010 Scaffolds with trace element for tissue regeneration in mammals WO/2011/0087772011.

[23] Hench LL, West JK 1990 The Sol-Gel Process Chem Rev $9033-72$

[24] Sepulveda P, Jones J R, Hench LL 2002 Bioactive sol-gel foams for tissue repair J Biomed Mater Res 592 340-348

[25] Poologasundarampillai G et al 2014 Cotton-wool-like bioactive glasses for bone regeneration Acta Biomater 108 3733-46

[26] Bao M, Lou X, Zhou Q et al., 2014 Electrospun biomimetic fibrous scaffold from shape memory polymer of 
PDLLA- co -TMC for bone tissue engineering," ACS Appl. Mater. Interfaces 64 2611-2621

[27] Bao M, Wang X, Yuan et al., 2016 HAp incorporated ultrafine polymeric fibers with shape memory effect for potential use in bone screw hole healing J. Mater. Chem. B 431 $5308-5320$

[28] Li W, Laurencin C T, Caterson E J, Tuan R S, Ko F K 2002 Electrospun nanofibrous structure : A novel scaffold for tissue engineering J Biomed Mater Res 604 613-21

[29] Bhardwaj N, Kundu S C 2010 Electrospinning: a fascinating fiber fabrication technique Biotechnol. Adv 283 $325-47$

[30] Kim H W, Lee H H, Chun G S 2008 Bioactivity and osteoblast responses of novel biomedical nanocomposites of bioactive glass nanofiber filled poly(lactic acid) J Biomed. Mater. Res. Part A, 853 651-663

[31] Agarwal S, Wendorff JH, Greiner A 2008 Use of electrospinning technique for biomedical applications Polymer (Guildf) $49265603-6521$

[32] Xie, J et al 2017 Collagen Gels with Different Fibrillar Microarchitectures Elicit Different Cellular Responses CS Appl. Mater. Interfaces 923 19630-19637

[33] Ki C S et al 2008 Development of 3-D nanofibrous fibroin scaffold with high porosity by electrospinning: Implications for bone regeneration Biotechnol. Lett 30 405-410

[34] Ji Y et al 2006 Electrospun three-dimensional hyaluronic acid nanofibrous scaffolds Biomaterials 27 3782-3792

[35] Srinivasan G 1994 Structure and morphology of electrospun polymer fibres University of Akron, $\mathrm{PhD}$ Thesis

[36] Reneker D H, Yarin L A, 2008 Electrospinning jets and polymer nanofibers Polymer (Guildf) 4910 2387-2425.

[37] Sakka S, Kozuka H 1988 Rheology of sols and fiber drawing J. Non. Cryst. Solids 100 1-3 142-153

[38] Bertoncelj V, Pelipenko J, Kristl J, Jeras M, Cukjati M, Kocbek P 2014 Development and bioevaluation of nanofibers with blood-derived growth factors for dermal wound healing Eur. J. Pharm. Biopharm 881 64-74

[39] Haider A, Haider S, Kang I K 2015 A comprehensive review summarizing the effect of electrospinning parameters and potential applications of nanofibers in biomedical and biotechnology Arabian Journal of Chemistry, King Saud University, p. https://doi.org/10.1016/j.arabjc.2015.11.015

[40] Pelipenko J et al 2013 The impact of relative humidity during electrospinning on the morphology and mechanical properties of nanofibers Int. J. Pharm 4561 125-134

[41] Huan S et al 2015 Effect of Experimental Parameters on Morphological, Mechanical and Hydrophobic Properties of Electrospun Polystyrene Fibers Materials (Basel) 8 2718-2734

[42] Macon ALB et al 2015 A unified in vitro evaluation for apatite-forming ability of bioactive glasses and their variants $J$. Mater. Sci. Mater. Med 262115

[43] Xie J, Bao M, Bruekers S et al 2017 Collagen Gels with Different Fibrillar Microarchitectures Elicit Different Cellular Responses ACS Appl. Mater. Interfaces 923 19630-19637

[44] Reneker DH et al 2000 Bending instability of electrically charged liquid jets of polymer solutions in electrospinning $J$ Appl. Phys 87 9 4531-4547

[45] Serra Jet al 2003 FTIR and XPS studies of bioactive silica based glasses J. Non. Cryst. Solids 332 1-3 20-27

[46] Martinex A et al 2000 Bioactivity of $\mathrm{CaO}-\mathrm{SiO} 2$ binary glasses system Chem. Mater 1211 3080-3088
[47] Hayashi T, Saito H 1980 Preparation of CaO-SiO glasses by the gel method J. Mater. Sci 15 1971-1977

[48] Lin S et al 2009 Nanostruture evolution and calcium distribution in sol-gel derived bioactive glass J. Mater. Chem 19 1276-82

[49] Connell LS et al 2014 Chemical characterisation and fabrication of chitosan-silica hybrid scaffolds with 3 glycidoxypropyl trimethoxysilane J. Mater. Chem B 26 668680

[50] Kirste G et al 2017 Effect of chloride ions in Tris buffer solution on bioactive glass apatite mineralization Int. J. Appl. Glas. Sci. 84 438-449

[51] K N, Bingel L, Groh D 2015 Influence of dissolution medium $\mathrm{pH}$ on ion release and apatite formation of Bioglass 45S5 Mater Lett 143 279-282

[52] M. F. Kulesz-Martin, D. Fabian, and J. S. Bertram, 1984 Differential Calcium Requirements for growth of mouse skin Epithelial and Fibroblasts Cells Cell Prolif 175 525-533

[53] Lusvardi G et al 2009 Fluoride-containing bioactive glasses: Surface reactivity in simulated body fluids solutions Acta Biomater $593548-3562$

[54] H. K. Ting et al., 2017 Phosphate content affects structure and bioactivity of sol-gel silicate bioactive glasses Int. J. Appl. Glas. Sci 84 372-382

[55] N. S. Chickerur, M. S. Tung, and W. E. Brown 1980 A mechanism for incorporation of carbonate into apatite Calcif. Tissue Int.32 55-62

[56] Ana Walt J D H, Rinn H W et al., 1938 Chemical Analysis by X-Ray Diffraction: Classification and Use of XRay Diffraction Patterns Ind. Eng. Chem. - Anal. Ed $109457-$ 512

[57] Midha S, Kim T B, Van Den Bergh W et al. 2013 Preconditioned 70S30C bioactive glass foams promote osteogenesis in vivo Acta Biomater., 911 9169-9182.

[58] Detsch R et al 2014 Increase in VEGF secretion from human fibroblast cells by bioactive glass S53P4 to stimulate angiogenesis in bone J. Biomed. Mater. Res. - Part A 10211 4055-4061

[59] Hoppe A, Güldal N S, Boccaccini A R 2011 A review of the biological response to ionic dissolution products from bioactive glasses and glass-ceramics," Biomaterials 3211 2757-2774 